\title{
Understanding the causes of negative tourism experiences
}

\author{
Abstract \\ The extant literature on destination attributes has seldom focused on negative tourism \\ experiences. Considering that negative tourism experiences result in undesirable future \\ behaviors, destination managers and researchers must understand the factors that influence \\ tourists' negative experiences. Therefore, this research examined the destination attributes \\ that influence visitors' negative experiences. A total of 298 travelogues were analyzed via an \\ a priori approach. We identified 16 destination attributes that result in negative tourism \\ experiences, including safety, price, quality of service, environment, physiography, culture \\ and history, infrastructure, accessibility, hospitality, variety of activities, weather, food, \\ tourist information, unethical business practices, regulations and customs, and visitor \\ management. The chi-square and correspondence analysis results show that these destination \\ attributes differ by contextual factors, such as the travel destination (domestic or international) \\ and travel type (independent or package tour). Theoretical and managerial implications are \\ discussed based on the study results, and directions for future research are provided.
}

Keywords: negative tourism experience, negative emotion, destination attributes, Chinese tourists, travel blog 


\section{Introduction}

The tourism industry, which offers tremendous benefits for economic development, has grown steadily around the world. For example, according to the World Tourism Cities Federation (WTOF), the number of tourists increased from 10.5 billion in 2016 to 12.1 billion in 2018, and the total tourism revenue increased from 5.17 trillion in 2016 to 5.34 trillion in 2018. Recognizing the growth of the tourism economy and the importance of delivering positive visitor experiences to enhance a destination's competitiveness in the marketplace (Kim, 2014, 2018; Kim et al., 2012; Oh et al., 2007), a common bias in the tourism literature is its preoccupation with examining tourists' positive experiences (Hosany \& Witham, 2010; Prayag \& Ryan, 2012). For example, sampling from cruise vacationers, Hosany and Witham (2010) found that educational, entertaining, esthetic, and escaping experiences influence satisfaction and one's intention to recommend. Furthermore, Prayag and Ryan (2012) identified destination attributes that determine tourists' satisfaction, such as cultural attractions, the variety and quality of accommodations, the quality of service, accessibility, and novelty. On the other hand, only a few researchers have studied negative kinds of tourism experiences while studying the drivers of both tourist satisfaction and dissatisfaction (Alegre \& Garau, 2010; Bianchi, 2016).

Neuburger, Zhang, and Fesenmaier (2018) argued that travelers experience both positive and negative emotions during their travel journeys. Furthermore, negative emotions have been reported to result in undesirable future behaviors, including switching and engaging in negative word-of-mouth (Sánchez-García \& Currás-Pérez, 2011). The memory literature also has suggested that negative valence leads to stronger memories than does positive valence (Kensinger et al., 2007; Levine \& Bluck, 2004). Thus, the topic of negative tourism experiences deserves attention from researchers. Specifically, considering that tourists 
experience negative emotions in response to their interpretations and evaluations of destination attributes experienced during their vacation, studying the attributes of a destination that influence visitors' negative experiences is critically important.

The other gap identified in the literature is the paucity of research sampling from Chinese tourists in examinations of negative tourism experiences. The existing studies on negative tourism experiences have been conducted mainly in Western cultural contexts (i.e., Europeans and Australians), with no research on China. There are two reasons for investigating Chinese tourists' negative tourism experiences in the current study. First, Chinese tourists' perceptions and preferences are significantly different from those of tourists from Western countries (Kim et al., 2010; Reisinger \& Mavondo, 2005). For example, Chinese and American customers differently evaluate levels of crowdedness, as Chinese customers tend to focus spatial factors (e.g., amount of the facilities), whereas American customers are sensitive to the number of people in a given space when evaluating crowdedness (Kim et al., 2010). Furthermore, by conducting a cross-cultural study, Turner et al. (2008) noted that cultural variance has an important role in determining tourist satisfaction. The second reason for studying Chinese tourists' negative experiences is the significance of the Chinese tourism market. According to the Ministry of Culture and Tourism of China, the number of outbound visitors and domestic tourists has increased steadily over the past five years. According to the Ministry of Culture and Tourism of China (2017), the number of outbound visitors increased from 981.852 million in 2013 to 1.305 billion in 2017, and the number of domestic tourists increased from 32.62 billion in 2013 to 50.01 billion in 2017. In terms of economic value, the total tourism revenue grew from 2.95 trillion RMB in 2013 to 5.4 trillion RMB in 2017.

With these issues in mind, this study examines the destination attributes that influence Chinese tourists' negative tourism experiences. The specific objectives of this study are 1) to 
develop a list of destination attributes that influence Chinese tourists' negative tourism experiences and 2) to further examine whether these identified destination attributes differ by tourism contexts, such as the travel destination (i.e., international vs. domestic) and travel type (i.e., independent vs. package tour).

\section{Literature Review}

\subsection{Destination Attributes and Negative Tourism Experiences}

Destination attributes are generally defined as an amalgam of the different elements of a tourism destination that attract travelers to the destination (Lew, 1987). In line with the stimuli-organism-response (S-O-R) theoretical framework (Mehrabian \& Russell, 1974) that explains how individuals' emotions and behavior are influenced by presented stimuli, previous tourism researchers have viewed destination attributes as critically important stimuli influencing tourists in different stages of their experiences (Kim, 2014). For example, the attractiveness of destination attributes significantly affects the formation of a destination image in the pre- and post-visit stages. Additionally, tourists' on-site experiences are determined by the performance of destination attributes. Accordingly, previous research has discussed the versatile roles of destination attributes in influencing tourist behavior (Assaf \& Josiassen, 2012; Bigne et al., 2001; Enright \& Newton, 2005; Lee et al., 2005).

Consistent with the growing trend emphasizing customer experiences (Haeckel et al., 2003; Pine \& Gilmore, 1999), the current study focuses on the influence of destination attributes on tourist experiences. In the extant tourism literature, previous researchers have developed destination attribute models focusing on a destination's ability to deliver pleasant and memorable experiences (Crouch \& Ritchie, 1999; Dwyer \& Kim, 2003; Enright \& 
Newton, 2004; Kim, 2014; Ritchie \& Crouch, 2003). The pioneering model is developed by Crouch and Ritchie (1999), including six dimensions: core resources and attractors; supporting factors and resources; destination management; destination policy, planning, and development; the competitive (micro) environment; and qualifying and amplifying determinants. Crouch (2011) later updated this model by including additional factors that may characterize the competitiveness of a destination. Recently, Kim (2014) developed a destination attributes model of the factors that may facilitate the formation of memorable tourism experiences.

These previous studies have advanced our understanding of destination attributes that influence positive tourism experiences. Thus, the extant models can guide destination managers towards the destination attributes that should be developed and managed to provide pleasant visitor experiences. However, one problem in the extant tourism literature is the lack of information on other kinds of tourism experiences (i.e., negative tourism experiences). Travelers have both positive and negative experiences during their stays in a destination. Furthermore, previous researchers have noted that the influence of negative consumer experiences is much greater than that of positive experiences on future behavior (Kim \& Chen, 2010). Recognizing the importance of negative experiences and the paucity of research addressing this issue, a few researchers have studied the causes of negative tourism experiences (Bianchi, 2016; George et al., 2010; Um \& Kim, 2018).

However, these studies on negative tourism experiences have been confined to a specific context, such as solo travelers and medical tourism. For example, Bianchi (2016) noted that safety, transportation, accommodation, and bad weather are determinants of solo holiday travelers' dissatisfaction. Furthermore, by applying fairness theory, Um and Kim (2018) found that outcome fairness is the strongest variable affecting medical tourists' dissatisfaction, followed by interpersonal, procedural, and informational fairness. Recently, Su and Teng 
(2018) utilized TripAdvisor online reviews to extract twelve service quality attributes that affect negative tourism experiences in museum settings. Furthermore, previous studies on destination attributes that affect negative tourism experiences have been conducted mainly in the Western context. For example, sampling from European tourists, Alegre and Garau (2010) identified the attributes of Mediterranean island destinations that influence visitor dissatisfaction, such as price, crowding, destruction of the landscape, cleanliness and hygiene. In summary, the identification of destination attributes that can explain negative tourism experiences in various contexts and can better explain Asian tourists' negative tourism experiences is needed, particularly among Chinese tourists, who have emerged as an important market segment (Wu \& Pearce, 2014).

\subsection{Cultural Differences in Tourist Experiences}

Previous researchers have noted that cultural values, which represent ideological perspectives including beliefs, norms, and customs that underlie and govern conduct in a society (Assael, 1995), exert a strong influence on tourists' interpretations of tourism products and direct tourist behavior (Ashworth, 1998; Kim et al., 2002). Thus, Wang et al. (2018) argued that Asian tourists should be considered culturally different and distinctive tourists, "not simply another wave of western minds, bodies and behaviors" (p. 431). In the literature, previous researchers have also provided empirical evidence to support this argument. For example, by conducting a cross-cultural study, Pizam and Jeong (1996) found that tourists from individualistic cultures, such as that of the U.S., preferred more dynamic and active tourism activities than those from collectivist cultures. Corroborating these findings, Xu et al. (2009) found that British college students prefer to engage in outdoor activities, shopping, and entertainment, whereas Chinese students prefer to appreciate cultural and historical attraction 
during their trips. Furthermore, Reisinger et al. (2009) found that Western and Asian tourists exhibit differences in evaluating destination attributes and consumption behavior. For example, Asian tourists seek safety and thus prefer to visit secure places and events. They also feel uncomfortable interacting with strangers. On the other hand, Western tourists seek new experiences and therefore take calculated risks and participate in more challenging activities. These two groups also show differences in destination service needs that determine their satisfaction with tourist services. For example, Asian tourists are more inclined to have services and programs tailored to their group needs, whereas those from Western countries are more interested in travel products tailored to individual needs.

Consistent with these previous findings, Zhang et al. (2015) confirmed that tourists' cultural backgrounds lead to diverse interpretations of landscape names and influenced their preferences. Specifically, tourists from cultures with high levels of power distance and low levels of individualism prefer landscape names that are mystic, dreamy, fictive, ingenious, original, and poetic, whereas their counterparts (i.e., tourists from cultures with low levels of power distance and high levels of individualism) prefer names that simply describe the landscape. Based on the above discussion, there is an important opportunity to advance our understanding of the destination attributes that affect Chinese tourists' negative tourism experiences, which may be significantly different from those that affect Western tourists' experiences.

\section{Methodology}

This study adopted an a priori approach to analyze the data, following the procedures recommended by Liu et al. (2015) and Sparks and Bradley (2017). We first developed a 
primary code book based on the existing literature and added new items that emerged from the data set. After coding, we used statistical tools to explore the relationships between the destination attributes and contextual factors.

\subsection{Data Collection}

We utilized the travelogues posted on Mafengwo, which is one of the most popular Chinese online tourism communities and has been confirmed as a reliable data source by previous researchers (Wu \& Pearce, 2014). Figure 1 shows the data collection, coding, and analysis procedures. We implemented the keyword search approach, a typical approach to retrieve online data in tourism research (Choi et al., 2007; Hunter, 2013), to retrieve relevant travelogues from Mafengwo. Two researchers developed a list of negative emotions based on an extensive literature review on negative emotions (see Appendix) owing to the strong causal relationship between negative tourism experience and negative emotions. Altogether, 298 travelogues were valid for data analysis. These travelogues were converted to word documents for further analysis in NVivo 12.

\section{[Insert Figure 1 About Here]}

\subsection{Data Coding}

This study involved two rounds of coding: open coding and axial coding. In the first data coding process, a researcher coded the relevant information on negative incidents using short sentences. Additionally, the travel characteristics (e.g., travel destination: domestic vs. international; travel type: independent vs. package tour) were coded. Since a few bloggers did not mention their travel type or destination, the numbers of total nodes reported in Table 3 
and Table 4 are different. Meanwhile, one researcher reviewed the current literature on destination management and tourist experiences and generated a primary code book containing a list of attributes affecting tourists' negative experiences. Axial coding was conducted by the two researchers independently to ensure a high level of inter-coder reliability. Then one of the researchers compared two separate coded documents to identify similarity and difference of all codes. The similarity of codes is $95.88 \%$. For the $4.12 \%$ of the disagreed codes, the third researcher was invited to review them and then provide comments. Finally, an accuracy of $100 \%$ was reached among three researchers.

During this process, the researchers identified some new destination attributes, such as regulations and customs, weather, and unethical business practices, from the data set. In addition, subcategories were identified for quality of service and unethical business practices to gain a deeper understanding of these attributes. Finally, a list of 16 destination attributes was developed in the code book (see Table 1).

[Insert Table 1 About Here]

\section{Results}

Table 2 reports the frequency of reports of the 16 destination attributes in the travel blogs. Based on the frequency analysis, they were grouped into four categories: high, moderate, lesser, and least frequency. 


\subsection{High-Frequency Destination Attributes}

\subsubsection{Unethical business practices}

Unethical business practices were found to be the most frequently reported issue leading to negative tourism experiences and as shown in Table 2, seven subcategories were identified. Fake and unfaithful representations (40.0\%) were associated with terms such as 'fake' and 'cheated'. More specifically, 'fake' concerned three main types of components, including products (e.g., fake artwork, diamonds, bus or attraction tickets, and taxi meters) and information (i.e., dishonest and fabricated information). Overcharging (20.8\%) was a problem referring to situations in which service staff asked for more money than what they had initially quoted. Downgrading or changing services without consulting tourists $(11.6 \%)$ commonly involved changing meals or itineraries to cheaper alternatives.

Restricted and forced shopping or optional tours $(9.3 \%)$ often occurred in package tours. Sometimes tourists were forced to stay at a shopping stop for at least one hour or to spend a minimum amount of money there. The last three subcategories were associated with the price attribute: businesspeople receiving substantial commissions (7.0\%), requests for tips $(6.4 \%)$, and price discrimination (4.9\%). Local businesspeople recommended certain attractions, hotels, shopping stops, optional tours, etc., to receive substantial commissions. For example,

We informed the coach driver of the hotel booking information, but he replied that 'this hotel is terrible'...he asked us to cancel the hotel booking and book another 'recommended' hotel (Travelogue 176). 
Travelers were requested to provide tips not only by service staff in service organizations but also by staff members of immigration counters of overseas destinations. Price discrimination is related to different price settings for different customers. For example, Chinese tourists were charged more than other foreign tourists in restaurants. Similarly, tourists were charged more than locals in restaurants.

\subsubsection{Quality of services}

Quality of services (23.3\%) includes nine subcategories (see Table 2). Specifically, issues related to tangibles and convenience involved poor-quality service facilities and unease while using the facilities. A lack of courtesy, responsiveness, assurance, empathy, reliability, and communication was reported in reference to the attitudes and behavior of service staff. Unobtrusiveness was related to both service facilities and service staff. Issues related to tangibles accounted for $33.6 \%$ of the negative service quality reports, and were mainly reported by tourists in hotels. For example,

The toilet was broken, so the bathroom was full of water...everything was wet (Travelogue 283).

Accounts of a lack of courtesy $(18.2 \%)$ referred to the poor attitudes and behavior of service staff during the service delivery process, such as violence, argumentativeness, and unfriendliness. Tourists also reported service staff's poor responsiveness (14.5\%) through the provision of slow service as well as their non-responsiveness. For example, some tourists had to wait for one hour to resolve a service failure that they had experienced. Furthermore, 
tourists indicated assurance-related problems $(12 \%)$ by describing service providers' lack of knowledge and professional skills. Other Chinese tourists reported a lack of empathy among service staff $(8.3 \%)$ as a cause for their negative tourism experiences. For instance, a staff member at a tourist attraction did not care about a group of tourists, even though the tourists were stuck on a mountain due to a snowstorm. Chinese tourists did not enjoy excessive welcoming by service staff or excessive commercial advertisements in hotel lobbies. These were examples related to a lack of unobtrusiveness (5.1\%). Reliability (4.1\%) issues were identified as issues related to the irresponsibility and unreliability of service staff.

Convenience $(3.0 \%)$ concerned uneasiness caused by services. For instance, a blogger shared,

Shaanxi Museum offers 3,000 physical tickets to tourists in the morning and another 3,000 in the afternoon. Even if you have an online ticket already, you still are required to collect a physical ticket in the ticket office before entering the attraction...(Travelogue 215)

Tourists also experienced communication (1.4\%) problems mainly related to language barriers in the service exchange context. For example, overseas service providers often cannot speak Chinese, and domestic service providers often cannot speak Mandarin (only Cantonese).

\subsection{Moderate-Frequency Destination Attributes}

Chinese tourists used the words 'expensive' and 'overpriced' when complaining about high prices $(8.6 \%)$. However, this evaluation was not based on absolute prices but by the value of products and services, which considers both the price and quality. Tourists also complained 
about food $(6.4 \%)$ at destinations. They were concerned about the poor quality and inauthenticity of food products, such as when food was stale, smelly, dirty, not tasty, lacking in variety, and served in a small portion. Poor visitor management (6.3\%) was also reported concerning overcapacity and crowd management. One travelogue elaborated an experience,

We queued for 2 hours to buy attraction tickets and waited for 1.5 hours to get to the shuttle bus in the attraction and then another 2 hours to get to the cable car...we spent the whole day queuing (Travelogue 280).

\subsection{Lesser-Frequency Destination Attributes}

The seven lesser-frequency attributes represented a range of $2 \%$ to $4.8 \%$ of the total frequency. The environment attribute $(4.8 \%)$ was related to the negative outward appearance of a destination, such as dirty streets (e.g., trash on the street) and dirty oceans and beaches (e.g., broken glass on the beach). These environmental descriptions also included unpleasant odors and the presence of many flies and mosquitoes at the destination. Tourists also reported weather $(3.7 \%)$ as a cause of their negative tourism experiences. For example, they indicated that bad weather conditions resulted in delays or cancelations of their schedules, which ultimately influenced their whole holiday experiences. Accessibility $(3.7 \%)$ issues, such as absent or limited public or private transportation, also caused negative experiences. One travel blogger described:

There is no taxi service outside the high-speed train station...The only thing I can do is catch a bus to the city (Travelogue 276) 
Expanding from the study of Dwyer \& Kim (2003), we identified a destination attribute on regulations and customs $(2.9 \%)$, which were related to rules, cultural norms and religious customs imposed by the government, society or service organizations (e.g., hotels, attractions, and restaurants). The regulations may have been effective and reasonable and have been implemented for a while; however, visitors viewed their enforcement as unreasonable due to limited information, different cultural backgrounds, etc. For example,

We didn't receive a certificate of temporary address from the hotel in Saint Petersburg...

When we had lunch in a restaurant, we were stopped by two policemen... They checked our passports and spotted that we didn't have the certificate of temporary address in Saint Petersburg, so they wanted to take us to the police station (Travelogue 286).

Unavailable and unreliable tourist information (2.7\%) wasted tourists' time, leading to their negative impressions of destinations. Few, unclear, or even incorrect road signs led to tourists' confusion in navigation within the destinations. Some tourists $(2.1 \%)$ attributed their negative tourism experiences to poor infrastructure at a destination. For example, they reported narrow and muddy roads, poor conditions of hiking routes and strange road designs without proper footpaths. Regarding safety $(2.0 \%)$, robbery was mentioned the most, resulting in the loss of valuables. Another safety concern was regarding driving issues, such as fast driving and negligent driving.

\subsection{Least-Frequency Destination Attributes}

Each of the four attributes in this group accounted for less than $2 \%$ of Chinese tourists' negative experiences. In this study, physiography (1.7\%) referred to negative evaluations of 
the natural landscape and scenery of a destination. For example, travel bloggers indicated their dissatisfaction with waterfalls, beaches, oceans, and islands by describing them as small, ordinary, poor or low quality. Furthermore, the culture and history attribute (1.6\%) focused on the low level of attractiveness of the culture and history of a destination. Examples included accounts of low-quality, inauthentic attractions at a cultural heritage site. Tourists also reported a lack of hospitality (1.0\%) from local people (e.g., unfriendliness and an unwelcoming attitude) as a source of their negative tourism experiences. Issues related to the variety of activities $(0.9 \%)$ appeared to be the least frequently reported destination attribute.

\subsection{Relationships between Destination Attributes and Contextual Factors}

The chi-square test was conducted to examine the significant differences in the destination attributes by different travel characteristics (the travel destination, i.e., domestic vs. international, as well as the travel type, i.e., independent vs. package tour). As shown in Table 3, international and domestic tourists showed significant differences in five destination attributes: visitor management, accessibility, infrastructure, tourist information, and physiography. Interestingly, domestic tourists experienced a higher percentage of these five attributes than international tourists. Furthermore, we found significant differences in the destination attributes that influenced negative tourism experiences by travel type: independent and package tour (see Table 4). Specifically, independent tourists were more likely to have negative tourism experiences due to issues of accessibility, tourist information, and infrastructure than package tourists, while package tourists were more likely to have negative experiences related to unethical practices in a destination. 
[Insert Table 3 About Here]

[Insert Table 4 About Here]

Correspondence analysis (CA) was conducted to further examine the relationship between the destination attributes and contextual factors. In correspondence analysis, k-1 dimensions are extracted based on the number of categories in the columns of a contingency table (Garson, 2001). Hair et al. (1998) suggested that singular values can be used as a criterion to determine dimensionality. The CA of Chinese tourists' negative tourism experiences by different context showed a two-dimensional solution. As shown in Table 5, the first and second dimensions explained, $63.6 \%$ and $22.6 \%$ of the variance and singular values of .300 and .179 respectively.

[Insert Table 5 About Here]

Table 6 presents the explanatory power of the two dimensions of the destination attributes. The attributes that explained less than $50 \%$ of the variance in each dimension were removed from the joint plot (Hair et al., 1998). In this case, it was decided to drop three destination attributes (i.e., culture and history, price, and safety) from the analysis. The results show that Dimension 1 explained large proportions of the variances in domesticindependent (.980) and international-package (.731) contexts; whereas Dimension 2 explained a comparatively higher proportion of the variance in domestic-package (.541) and international-independent (.629) contexts. As shown in Figure 2, the first principal axis 
clearly separated domestic-independent tour from domestic-package, international-package and international-independent tours. Clearly, the international-package tour and domesticpackage tour contexts are associated with unethical business practices. On the other hand, domestic-independent tour is closely related to tourist information, infrastructure, accessibility, food, variety of activities, visitor management, and physiography. The second principal axis separated international-independent tour from the rest three travel contexts. Specifically, the international-independent context is strongly related to the environment and regulations and customs.

[Insert Table 6 About Here]

[Insert Figure 2 About Here]

\section{Conclusion and Discussion}

\subsection{Theoretical Implications}

The current study makes academic contributions in several ways. First, this study extended existing destination competitiveness models by specifically focusing on negative tourism experiences. According to the "motivator and hygiene theory" (Herzberg, et al., 1959), the opposite of satisfaction is no more dissatisfaction than the opposite of dissatisfaction is satisfaction. In other words, destination attributes leading to positive tourism experiences could be different from those resulting in negative tourism experiences. In support of this statement, we found that the destination attributes of local culture and history, mix of activities (Crouch, 2011; Kim, 2014), and hospitality (Kim, 2014) that have been found to be important for providing positive tourism experiences were reported infrequently in tourists' 
shared descriptions of their negative tourism experiences. Thus, this study contributed to the tourism literature by developing a list of 16 destination attributes that influence negative tourism experiences.

We also extended the destination attribute research by discussing the factors leading to Chinese tourists' negative tourism experiences. Although some of the destination attributes we found in this study overlap with those reported in previous studies conducted in Western contexts (Bianchi, 2016; Korzay \& Alvarez, 2005), our results showed some unique aspects of Chinese tourists' negative experiences. For example, unethical business practices were not discussed as a cause of Westerners' negative tourism experiences (e.g., Bianchi, 2016; Alegre \& Garau, 2010); however, we found that this attribute was the most frequently reported in describing negative tourism experiences. This result can be explained by Chinese cultural values. For example, Chinese cultural values emphasize righteousness, which emphasizes mutual profitableness instead of self-interest (Hsu, 2007). Furthermore, Chinese cultural values hold that people should be honest and refuse to cheat others (Zhao et al., 2011).

In addition, we found that poor service quality was the other destination attribute that was more frequently reported than the other attributes. In China, propriety (in Chinese, li “礼”) provides essential societal guidelines involving ideals, ethics, social norms, values, etiquette, politeness, and regulations for regimes, state institutions, and hierarchies (Warner $\&$ Zhu, 2002). This cultural value can explain Chinese tourists' attribution of their negative experiences to service staff's unfriendliness and discourtesy. Furthermore, Chinese cultural values uphold a sense of obligation (Fan, 2000). Accordingly, Chinese visitors become easily annoyed in reaction to the irresponsiveness of service staff, as they think the service staff is being negligent in their duties. Other-centeredness, which emphasizes thoughtfulness for others, is another important Chinese cultural value (Quek \& Storm, 2012). Thus, in a service 
organization, a service staff member's careless attitude and/or behaviour as well as his or her lack of empathy are not acceptable for Chinese tourists.

\subsection{Practical Implications}

In addition to the theoretical implications, this study also yields some practical implications for destination managers. First, the study findings suggest that unethical business practices represent the most important category in negative tourism experiences. Thus, destination managers, policy makers, and merchants should work together to develop a healthy market. Destination managers can develop educational programs to improve business ethics with a focus on reducing the practices of 'overcharging' and 'downgrading or changing services without consulting with tourists'. More importantly, service staff should be trained to earn profits by providing quality products and services to consumers instead of forcing customers to provide tips or relying on receiving commissions. On the other hand, destination managers should let tourists know what they can do in the unfortunate event that they experience unethical business practices. In this context, tourists should be strongly aware of the need to protect themselves rather than being tolerant, which in turn will help destination managers better regulate business practices.

We also found that service quality was a significant determinant of negative tourism experiences. Particularly, travel bloggers frequently reported tangible aspects of quality service, such as broken or deficient service facilities. Therefore, management personnel of service organizations should offer adequate, well-functioning facilities to their customers and at the same time, train service staff to provide courteous, careful, efficient, and reliable service to their customers. Moreover, we found that high prices had a negative effect on tourism experiences. This finding does not indicate the need to lower prices but rather a 
reasonable price that corresponds to the value of the products and services. Thus, businesses in a destination should determine the prices for their products by considering customers' perceived value of them. In addition, destination managers should strive to control the capacity level of a destination. As previous research has suggested, Chinese individuals are likely to evaluate crowdedness based on spatial factors (e.g., the structure and design of a restaurant) and thus, it is essential to make them feel that an attraction is well organized and managed.

\subsection{Limitations and Future Research}

Inevitably, this study has certain limitations. First, utilizing travelogues as the data source limits the generalizability of the study findings. Thus, to ensure external validity, employing samples of nonbloggers, such as interviewing Chinese nonbloggers' negative tourism experience, is needed in future studies. Second, all travelogues were retrieved from Mafengwo.com, in which demographic information of bloggers, such as gender and age, is missing. Therefore, analyzing the linkage between travelogue content and demographic information from other tourism communities could demonstrate an in-depth understanding of tourists' negative tourism experience. Third, as the purpose of the current study was to obtain rich descriptions of negative tourism experiences, this study is limited to being exploratory in nature. Further quantitative studies could be conducted to test the results. Finally, this study only used negative emotional reactions as keywords to search relevant negative tourism travelogues. Future studies could research different types of negative emotion from 
travelogues, as well as investigate the causal relationships between the identified destination attributes and negative emotions as well as negative future behaviours. 
Appendix. Negative emotional word list

\begin{tabular}{|c|c|}
\hline $\begin{array}{l}\text { Negative emotional } \\
\text { reactions in English }\end{array}$ & Relevant words in Chinese \\
\hline Angry & 生气、反感、可恨、可恶至极、无耻、气愤 \\
\hline Contemptuous & 强烈地谴责、强烈鄙视 \\
\hline Desperate & 绝望 \\
\hline Disappointed & 失望、合、坑、心好塞、痛苦、闹心、寒心、阴影 \\
\hline Discontented & 不满意、够够的、心烦、心烦意乱、心碎 \\
\hline Irritated & 头疼、崩溃、崩溃、彻底崩溃、忍受不了、痛苦不堪、贪婪 \\
\hline Mad & 抓狂、捶胸顿足 \\
\hline Unhappy & 不开心、谷、坑、情绪低落、烦人、烦死人、烦躁、烦闷、糟心 \\
\hline Uncomfortable & 心力交瘁、心累 \\
\hline Tense/Nervous & 精神紧张、紧张 \\
\hline Afraid & 心慌、害怕、焦躁 \\
\hline Horrified & 恐怖 \\
\hline Panicky & 慌张 \\
\hline Scared & 害怕、太可怕了、好怕怕 \\
\hline Worried/Anxious & 担心、很难让人安心、点态 \\
\hline Bored & 无聊 \\
\hline Confused & 懵逼 \\
\hline Depressed & 压抑、郁闷 \\
\hline Disgusted & 恶心 \\
\hline Embarrassed & 䏒尴迄、狼狈、难堪 \\
\hline Hateful & 厌倦 \\
\hline Helpless & 无奈 \\
\hline Miserable & 悲惨、可悲、委屈、忍着 \\
\hline Pity & 可惜、太二了 \\
\hline Regretful & 懊恼 \\
\hline Sad & 心酸、悲摧、悲哀、痛心、辛酸 \\
\hline Shamed & 丟脸、蒙羞 \\
\hline Shocked & 蒙了、震惊、蒙圈 \\
\hline
\end{tabular}

Sources: (Breitsohl \& Garrod, 2016; Laros \& Steenkamp, 2005; Jang \& Namkung, 2009). 


\section{References}

Alegre, J., \& Garau, J. (2010). Tourist satisfaction and dissatisfaction. Annals of Tourism Research, 37(1), 52-73.

Assaf, G.A., \& Josiassen, A. (2012). European vs. U.S. airlines: performance comparison in a dynamic market. Tourism Management, 33(2), 317-326.

Becken, S. (2012). Measuring the effect of weather on tourism. Journal of Travel Research, $52(2), 156-167$.

Bianchi, C. (2016). Solo holiday travellers: Motivators and drivers of satisfaction and dissatisfaction. International Journal of Tourism Research, 18(2), 197-208.

Bigne, J.E., Sanchez, M.I., \& Sanchez, J. (2001). Tourism image, evaluation variables and after purchase behavior: Inter-relationship. Tourism Management, 22(6), 607-616.

Christou, P., \& Sharpley, R. (2019). Philoxenia offered to tourists? A rural tourism perspective. Tourism Management, 72, 39-51.

Chung, B., \& Hoffman, K.D. (1998). Critical incidents. Cornell Hotel and Restaurant Administration Quarterly, 39(3), 66-71.

Crouch, G.I. (2011). Destination competitiveness: an analysis of determinant attributes. Journal of Travel Research, 50(1), 27-45.

Crouch, G.I., \& Ritchie, J.R.B. (1999). Tourism, competitiveness, and societal prosperity. Journal of Business Research, 44(3), 137-152.

Dwyer, L., \& Kim, C. (2003). Destination competitiveness: determinants and indicators. Current Issues in Tourism, 6(5), 369-414.

Enright, M.J., \& Newton, J. (2004). Tourism destination competitiveness: a quantitative approach. Tourism Management, 25(6), 777-788.

Enright, M.J., \& Newton, J. (2005). Determinants of tourism destination competitiveness in Asia Pacific: comprehensiveness and universality. Journal of Travel Research, 43(4), 339-350.

Fan, Y. (2000). A classification of Chinese culture. Cross Cultural Management: An International Journal, 7(2), 3-10.

Faulkner, B., Wilks, J., \& Page, S. (2001). Towards a framework for tourism disaster management. Tourism Management, 22(2), 135-147.

Haeckel, S.H., Carbone, L.P., \& Berry, L.L. (2003). How to lead the customer experience. Marketing Management, 12(1), 18-18. 
Hair, J.F., Anderson, R.E., Tatham, R.L., \& Black, W.C. (1998). Multivariate data analysis (5th ed.). Upper Saddle River, NJ: Prentice-Hall.

Hosany, S., \& Witham, M. (2010). Dimensions of cruisers' experiences, satisfaction, and intention to recommend. Journal of Travel Research, 49(3), 351-364.

Hunter, W.C. (2013). China's Chairman Mao: A visual analysis of Hunan Province online destination image. Tourism Management, 34, 101-111.

Kensinger, E.A., Rachel J. Garoff-Eaton, \& Schacter, D.L. (2007). How negative emotion enhances the visual specificity of a memory. Journal of Cognitive Neuroscience 19(11), 1872-1887.

Kim, D.Y., Wen, L., \& Doh, K.R. (2010). Does cultural difference affect customer's response in a crowded restaurant environment? A comparison of American versus Chinese customers. Journal of Hospitality \& Tourism Research, 34(1), 103-123.

Kim, J.-H. (2014). The antecedents of memorable tourism experiences: The development of a scale to measure the destination attributes associated with memorable experiences. Tourism Management, 44, 34-45.

Kim, J.-H. (2018). The impact of memorable tourism experiences on loyalty behaviors: the mediating effects of destination image and satisfaction. Journal of Travel Research, 57(7), 856-870.

Kim, J.-H., \& Chen, J.S. (2010). The effects of situational and personal characteristics on consumer complaint behavior in restaurant services. Journal of Travel \& Tourism Marketing, 27(1), 96-112

Kim, J.-H., Ritchie, J.R.B., \& McCormick, B. (2012). Development of a scale to measure memorable tourism experiences. Journal of Travel Research, 51(1), 12-25.

Kim, S.S., Prideaux, B., \& Kim, S.H. (2002). A cross-cultural study on casino guests as perceived by casino employees. Tourism Management, 23(5), 511-520.

King, B., Dwyer, L., \& Prideaux, B. (2006). An evaluation of unethical business practices in Australia's China inbound tourism market. International Journal of Tourism Research, $8(2), 127-142$.

Lee, C., Lee, Y., \& Lee, B. (2005). Korea's destination image formed by the 2002 World Cup. Annals of Tourism Research, 32(4), 839-858.

Levine, L.J., \& Bluck, S. (2004). How emotions fade: Valence, appraisals, and the emotional impact of remembered events. Advances in Psychology Research, 30, 3-20.

Lew, A.A. (1987). A framework of tourist attraction research. Annals of Tourism Research, 14, 
$553-575$.

Liu, B., Kim, H., \& Pennington-Gray, L. (2015). Responding to the bed bug crisis in social media. International Journal of Hospitality Management, 47, 76-84.

Mehrabian, A., Russell, J. A., 1974. An approach to environmental psychology. The MIT Press.

Mihalič, T. (2000). Environmental management of a tourist destination: a factor of tourism competitiveness. Tourism Management, 21(1), 65-78.

Ministry of Culture and Tourism of China (2017). Retrieved on April 6, 2019 from http://zwgk.mct.gov.cn/auto255/201802/t20180206_832375.html?keywords=

Neuburger, L., Zhang, W., \& Fesenmaier, D.R. (2018). Emotions and the defining features of overall tourism experiences. In: Tourism Travel and Research Association.

Oh, H., Fiore, A.M., \& Jeoung, M. (2007). Measuring experience economy concepts: tourism applications. Journal of Travel Research, 46(2), 119-132.

Parasuraman, A., Zeithaml, V.A., \& Berry, L.L. (1988). 'SERVQUAL: A Multiple-item scale for measuring consumer perceptions of service quality'. Journal of Retailing, 64(1), $12-40$.

Pine, B.J., \& Gilmore, J.H. (1999). The experience economy: Work is theatre \& every business a stage. Harvard Business Press.

Prayag, G., \& Ryan, C. (2012). Antecedents of tourists' loyalty to Mauritius: The role and influence of destination image, place attachment, personal involvement, and satisfaction. Journal of Travel Research, 51(3), 342-356.

Quek, M.-T., \& Storm, C.L. (2012). Chinese values in supervisory discourse: Implications for culturally sensitive practices. Contemporary Family Therapy, 34(1), 44-56.

Reisinger, Y., \& Mavondo, F. (2005). Travel anxiety and intentions to travel internationally: Implications of travel risk perception. Journal of Travel Research, 43(1), 212-225.

Reisinger, Y., Mavondo, F., \& Crotts, J.C. (2009). The importance of destination attributes: Western and Asian visitors. Anatolia, 20(1), 236-253.

Ritchie, J.R.B., \& Crouch, G.I. (2003). The competitive destination: A sustainable tourism perspective: $\mathrm{CABI}$.

Ritchie, J.R.B., \& Zins, M. (1978). Culture as determinant of the attractiveness of a tourism region. Annals of Tourism Research, 5(2), 252-267.

Sánchez-García, I., \& Currás-Pérez, R. (2011). Effects of dissatisfaction in tourist services: The role of anger and regret. Tourism Management, 32(6), 1397-1406. 
Smith, S.L.J. (1994). The tourism product. Annals of Tourism Research, 21(3), 582-595.

Sparks, B.A., \& Bradley, G.L. (2017). A “Triple A” typology of responding to negative consumer-generated online reviews. Journal of Hospitality \& Tourism Research, 41(6), 719-745.

Su, Y., \& Teng, W. (2018). Contemplating museums' service failure: Extracting the service quality dimensions of museums from negative on-line reviews. Tourism Management, 69, 214-222.

Tsang, N., \& Qu, H. (2000). Service quality in China's hotel industry: A perspective from tourists and hotel managers. International Journal of Contemporary Hospitality Management, 12(5), 316-326.

Turner, L.W., Reisinger, Y.V., \& McQuilken, L. (2008). How cultural differences cause dimensions of tourism satisfaction. Journal of Travel \& Tourism Marketing, 11(1), 79101.

Wang, W., Yi, L., Wu, M.-Y., Pearce, P.L., \& Huang, S. (2018). Examining Chinese adult children's motivations for traveling with their parents. Tourism Management, 69, 422433.

Wu, M.Y., \& Pearce, P.L. (2014). Appraising netnography: towards insights about new markets in the digital tourist era. Current Issues in Tourism, 17(5), 463-474.

Xu, F.F., Morgan, M., \& Ping, S. (2009). Students' travel behaviour: a cross-cultural comparison of UK and China. International Journal of Tourism Research, 11(3), 255-

Zhang, C.Z., Gursoy, D., Zeng, D., \& Gao, J. (2015). Impact of culture on perceptions of landscape names. Tourism Geographies, 17(1), 134-150. 
Table 1. Definitions of the potential destination attributes that affect negative tourism experiences

\begin{tabular}{|c|c|c|}
\hline Destination attributes & Operational definitions & Relevant literature \\
\hline Safety & $\begin{array}{l}\text { Destinations should be able to make tourists feel safe and secure at all times time during their } \\
\text { stay. }\end{array}$ & $\begin{array}{l}\text { Crotts, 2003; Crouch \& Ritchie, 1999; } \\
\text { Faulkner et al., 2001; Kim, } 2014\end{array}$ \\
\hline Price & $\begin{array}{l}\text { This attribute does not refer to the lowest price but rather a reasonable price that corresponds to } \\
\text { the quality of the products of a destination. }\end{array}$ & $\begin{array}{l}\text { Driscoll et al., 1994; Dwyer \& Kim, } \\
\text { 2003; Kim, } 2014\end{array}$ \\
\hline Quality of service & $\begin{array}{l}\text { The quality of service is problematic when service organizations in a destination provide } \\
\text { unreliable, irresponsive, and unfriendly service to visitors. This attribute has } 9 \text { potential } \\
\text { dimensions: tangibles, reliability, responsiveness, assurance, empathy, communication, } \\
\text { courtesy, convenience, and unobtrusiveness. }\end{array}$ & $\begin{array}{l}\text { Dwyer \& Kim, 2003; Kim, 2014; } \\
\text { Parasuraman et al., 1988; }\end{array}$ \\
\hline Environment & $\begin{array}{l}\text { This attribute refers to an ill-managed environment of a destination that would result in negative } \\
\text { tourism experiences. }\end{array}$ & $\begin{array}{l}\text { Driscoll et al., 1994; Dwyer \& Kim, } \\
\text { 2003; Kim, 2014; Mihalič, } 2000\end{array}$ \\
\hline Physiography & $\begin{array}{l}\text { This attribute refers to destinations that have unattractive, unaesthetic, and not visually } \\
\text { appealing resources. }\end{array}$ & $\begin{array}{l}\text { Crouch \& Ritchie, 1999; Dwyer \& Kim, } \\
2003\end{array}$ \\
\hline Culture and history & $\begin{array}{l}\text { This attribute is defined by time and history (e.g., heritage, traditions, religion) and requires } \\
\text { little or no alterations. Indistinctive and inauthentic culture and history could lead to } \\
\text { homogenized tourism. }\end{array}$ & Crouch \& Ritchie, 1999 \\
\hline Infrastructure & $\begin{array}{l}\text { Infrastructure is part of the larger macroenvironment, including the water supply, electricity } \\
\text { generation system, airport, and healthcare facilities. }\end{array}$ & $\begin{array}{l}\text { Crouch, 2011; Dwyer \& Kim, 2003; } \\
\text { Smith, } 1994\end{array}$ \\
\hline Accessibility & $\begin{array}{l}\text { This attribute refers to unease in and low-quality access to a destination as well as within a } \\
\text { destination. }\end{array}$ & Kim, 2014; Ritchie \& Zins, 1978 \\
\hline
\end{tabular}


Hospitality

Mix of activities

Weather

Food

Tourist information

Unethical business practices

Undesirable incidents

Regulations and customs

Visitor management
This attribute influences negative experiences when tourists perceive the local people to be unfriendly and the community to have a bad attitude. Tourists perceive a cold reception through their interactions with local people and are regarded and treated as customers rather than friends.

This attribute refers to destinations' inability to provide diverse tourism activities to their visitors.

Bad weather can be an inhibitor to tourism activities. Too high/low temperature, unexpected precipitation, or other weather changes negatively influence tourism experiences.

This attribute refers to inauthentic and/or low-quality food provided by food outlets, food stores, and restaurants in a destination.

This attribute refers to the unavailability (including of different language versions of tourist information) and unreliability of information provided in a destination.

Unethical business practices refer to a business's engagement in behavior that does not fall within the accepted rules of conduct that prevail both in the local industry and the society at large.

This attribute refers to a negative unforeseeable event or a situation that experienced by tourists while traveling (e.g., lost valuables, injury, or illness).

This attribute refers the enforcement of customs in a destination that are unreasonable or not understandable from tourists' perspectives.

Unsuccessful visitor management refers to destinations' failures to maintain a personal touch wherever possible, including preventing visitors from having to stand in long lines of from feeling like they are being "herded" and are in chaos at popular venues, to ensure the constant quality of visitor experiences.
Christou \& Sharpley, 2019; Dwyer \& Kim, 2003; Kim, 2014

Crouch, 2011; Dwyer \& Kim, 2003; Kim, 2014

Becken, 2012; Kozak \& Rimmington, 1999; McKercher et al., 2014

Dwyer \& Kim, 2003

Dwyer \& Kim, 2003

Tourism Queensland, 1999; King et al., 2006; March, 2008

Chung \& Hoffman, 1998; Kim, 2014

Dwyer \& Kim, 2003

Ritchie \& Crouch, 2003 
Table 2. Destination attributes affecting tourists' negative experiences 


\begin{tabular}{lccc}
\hline Destination attributes and quotations & Frequency & Percentage & $\begin{array}{c}\text { Level of } \\
\text { Frequency }\end{array}$ \\
\hline Unethical business practices & 528 & 28.3 & High
\end{tabular}

Our tour guide wanted to promote Lingzhi mushroom, so lied to us that her father had liver cancer before, and her father lost $2 / 3$ of his liver after the operation. After taking the Lingzhi mushroom, her father fully recovered and had a new and full liver now (Travelogue 171).

Fake or misleading representations

Overcharging

Downgrades or changes in service without

consulting tourists

Restricted and forced shopping and/or optional

tours

Businesspeople receiving substantial commissions

Requests for tips

$\begin{array}{cc}211 & 40.0 \\ 110 & 20.8 \\ 61 & 11.6 \\ 49 & 9.3 \\ 37 & 7.0 \\ 34 & 6.4 \\ 26 & 4.9\end{array}$

Quality of services

435

23.3

High

We left the hotel at $8.30 \mathrm{am} . .$. the tour guide forgot to bring our passports so we were not able to visit the attraction of Military Demarcation Line... the schedule was cancelled... we wasted for a half day... (Travelogue 112)

Tangibles

Courtesy

Responsiveness

Assurance

Empathy

Unobtrusiveness

Reliability

Convenience

Communication

Local people asked us to use their private car to go to the mountain. They charged $10 \mathrm{RMB}$ per person for the service, altogether we paid $40 \mathrm{RMB}$, but the trip only took 1 minute (Travelogue 41).

Food

There were a few oysters in the oyster omelette, which 
smelt so weird. The sauce was disgusting (Travelogue 122).

Visitor management

We queued for 2 hours to buy attraction tickets and waited for 1.5 hours to get to the shuttle bus in the attraction and then another 2 hours to get to the cable car...we spent the whole day queuing (Travelogue 280).

Environment

The sea water around the White Sand Doclet Resort is not clear, which was not good for scuba diving (Travelogue 106).

\section{Weather}

It should be cloudy based on the weather forecast on that day; however, we just experienced a storm, which disturbed our schedule (Travelogue 131).

Accessibility

Lesser

There is no taxi service outside the high-speed train station... The only thing I can do is catch a bus to the city (Travelogue 276)

Regulations and customs

We didn't receive a certificate of temporary address from the hotel in Saint Petersburg... When we had lunch in a restaurant, we were stopped by two policemen... They checked our passports and spotted that we didn't have the certificate of temporary address in Saint Petersburg, so they wanted to take us to the police station (Travelogue 286).

\section{Tourist information}

We were planning to visit the Great Wall from Tiananmen Square. However, we can't find the bus stop due to a lack of clear signals (Travelogue 136).

Infrastructure

Moderate

$4.8 \quad$ Lesser

3.7 Lesser

70

Lesser

Lesser

There are too many traffic lights and lots of one-way streets in Edinburgh (Travelogue 232). 
Three of us walked together on the way to a convenience store, suddenly, I felt that someone was pulling my bag. When I turned back, I just found that a man riding on a motorbike had got my bag which includes my passport, ID, cash, and camera) (Travelogue 164).

Physiography

The forest park is so normal. In my mind, the forest park should be an old-growth forest. I was disappointed

(Travelogue 126).

Culture and history

All of the terracotta warriors are replicas in the attraction of Xi'an Incident Memorial Hall, which are so fake (Travelogue 130).

\section{Hospitality}

We were unable to find our hotel, so we asked a local lady to help, but she requested $20 \mathrm{RMB}$ for guiding (Travelogue 1).

\section{Mix of activities}

Xingping Old Town is boring, where we can't see and do much. To be honest, the town should be called 'Xingping Old Street', which is around 100 meters. I finished my visit in a few minutes (Travelogue 91). 
Table 3. Chi-square test of the destination attributes by travel destination

\begin{tabular}{|c|c|c|c|c|c|}
\hline Destination attributes & $\begin{array}{l}\text { Domestic } \\
\text { (frequency) }\end{array}$ & $\begin{array}{l}\text { International } \\
\text { (frequency) }\end{array}$ & $\begin{array}{l}\text { Domestic } \\
\text { (percentage) }\end{array}$ & $\begin{array}{l}\text { International } \\
\text { (percentage) }\end{array}$ & $p$-value \\
\hline Unethical business practices & 181 & 139 & 21.8 & 26.1 & 0.400 \\
\hline Quality of services & 174 & 146 & 21.0 & 27.4 & 0.221 \\
\hline Price & 79 & 58 & 9.5 & 10.9 & 0.672 \\
\hline Food & 63 & 33 & 7.6 & 6.2 & 0.574 \\
\hline Visitor management & 61 & 12 & 7.4 & 2.3 & 0.001 \\
\hline Environment & 36 & 36 & 4.3 & 6.8 & 0.338 \\
\hline Weather & 35 & 12 & 4.2 & 2.3 & 0.210 \\
\hline Accessibility & 44 & 10 & 5.3 & 1.9 & 0.014 \\
\hline Regulations and customs & 23 & 26 & 2.8 & 4.9 & 0.343 \\
\hline Tourist information & 32 & 7 & 3.9 & 1.3 & 0.023 \\
\hline Infrastructure & 28 & 6 & 3.4 & 1.1 & 0.028 \\
\hline Safety & 9 & 23 & 1.1 & 4.3 & 0.123 \\
\hline Physiography & 25 & 4 & 3.0 & 0.8 & 0.014 \\
\hline Culture and history & 17 & 9 & 2.1 & 1.7 & 0.759 \\
\hline Hospitality & 10 & 8 & 1.2 & 1.5 & 0.806 \\
\hline Mix of activities & 12 & 3 & 1.4 & 0.6 & 0.302 \\
\hline Total & 829 & 532 & 100 & 100 & \\
\hline
\end{tabular}


Table 4. Chi-square test of the destination attributes by travel type

\begin{tabular}{|c|c|c|c|c|c|}
\hline Destination attributes & $\begin{array}{c}\text { Independent } \\
\text { (frequency) }\end{array}$ & $\begin{array}{l}\text { Package tour } \\
\text { (frequency) }\end{array}$ & $\begin{array}{l}\text { Independent } \\
\text { (percentage) }\end{array}$ & $\begin{array}{l}\text { Package tour } \\
\text { (percentage) }\end{array}$ & $p$-value \\
\hline $\begin{array}{l}\text { Unethical business } \\
\text { practices }\end{array}$ & 150 & 144 & 17.6 & 32.7 & 0.008 \\
\hline Quality of services & 191 & 111 & 22.4 & 25.2 & 0.577 \\
\hline Price & 90 & 41 & 10.6 & 9.3 & 0.670 \\
\hline Food & 70 & 22 & 8.2 & 5.0 & 0.152 \\
\hline Visitor management & 51 & 21 & 6.0 & 4.8 & 0.584 \\
\hline Environment & 49 & 21 & 5.8 & 4.8 & 0.648 \\
\hline Weather & 29 & 17 & 3.4 & 3.9 & 0.800 \\
\hline Accessibility & 45 & 7 & 5.3 & 1.6 & 0.003 \\
\hline $\begin{array}{l}\text { Regulations and } \\
\text { customs }\end{array}$ & 37 & 11 & 4.3 & 2.5 & 0.255 \\
\hline Tourist information & 35 & 3 & 4.1 & 0.7 & 0.000 \\
\hline Infrastructure & 30 & 3 & 3.5 & 0.7 & 0.001 \\
\hline Safety & 18 & 12 & 2.1 & 2.7 & 0.715 \\
\hline Physiography & 21 & 8 & 2.5 & 1.8 & 0.602 \\
\hline Culture and history & 11 & 13 & 1.3 & 3.0 & 0.326 \\
\hline Hospitality & 15 & 2 & 1.8 & 0.5 & 0.066 \\
\hline Mix of activities & 10 & 4 & 1.2 & 0.9 & 0.752 \\
\hline Total & 852 & 440 & 100 & 100 & \\
\hline
\end{tabular}


Table 5. Summary of the dimension results

\begin{tabular}{lcccccr}
\hline & & & \multicolumn{2}{c}{ Proportion of Inertia } & & \\
\cline { 4 - 5 } Dimension & Singular value & Inertia & Explained & Cumulative & Chi-square & Sig. \\
\hline 1 & .300 & .090 & .636 & .636 & & \\
2 & .179 & .032 & .226 & .861 & & \\
3 & .140 & .020 & .139 & 1.000 & & \\
Total & & .142 & 1.000 & 1.000 & 183.22 & $.000^{\mathrm{a}}$ \\
\hline
\end{tabular}


Table 6. Contribution of the dimensions to the inertia of each destination attribute

\begin{tabular}{|c|c|c|c|c|}
\hline Destination attributes & Mass & $\begin{array}{l}\text { Explanation by } \\
\text { dimension } 1\end{array}$ & $\begin{array}{c}\text { Explanation by } \\
\text { dimension } 2\end{array}$ & Total \\
\hline Accessibility & .040 & .997 & .001 & .997 \\
\hline Culture and history & .019 & .176 & .469 & .645 \\
\hline Environment & .054 & .094 & .628 & .721 \\
\hline Food & .071 & .763 & .117 & .879 \\
\hline Hospitality & .013 & .283 & .701 & .984 \\
\hline Infrastructure & .026 & .956 & .003 & .959 \\
\hline Mix of activities & .011 & .593 & .138 & .731 \\
\hline Physiography & .022 & .749 & .245 & .994 \\
\hline Price & .101 & .025 & .196 & .221 \\
\hline Quality of services & .234 & .736 & .123 & .859 \\
\hline Regulations and customs & .037 & .036 & .824 & .860 \\
\hline Safety & .023 & .275 & .164 & .439 \\
\hline Tourist information & .029 & .968 & .032 & 1.000 \\
\hline Unethical business practices & .228 & .724 & .276 & 1.000 \\
\hline Visitor management & .056 & .694 & .280 & .974 \\
\hline Weather & .036 & .277 & .718 & .995 \\
\hline Active Total & 1.000 & & & \\
\hline Contextual factors & Mass & $\begin{array}{l}\text { Explanation by } \\
\text { dimension } 1\end{array}$ & $\begin{array}{l}\text { Explanation by } \\
\text { dimension } 2\end{array}$ & Total \\
\hline Domestic-Independent & .426 & .980 & .001 & .981 \\
\hline Domestic-Package & .193 & .245 & .541 & .786 \\
\hline International-Independent & .234 & .269 & .629 & .898 \\
\hline International-Package & .147 & .731 & .008 & .739 \\
\hline Active Total & 1.000 & & & \\
\hline
\end{tabular}


Figure 1. Data collection, coding and analysis processes

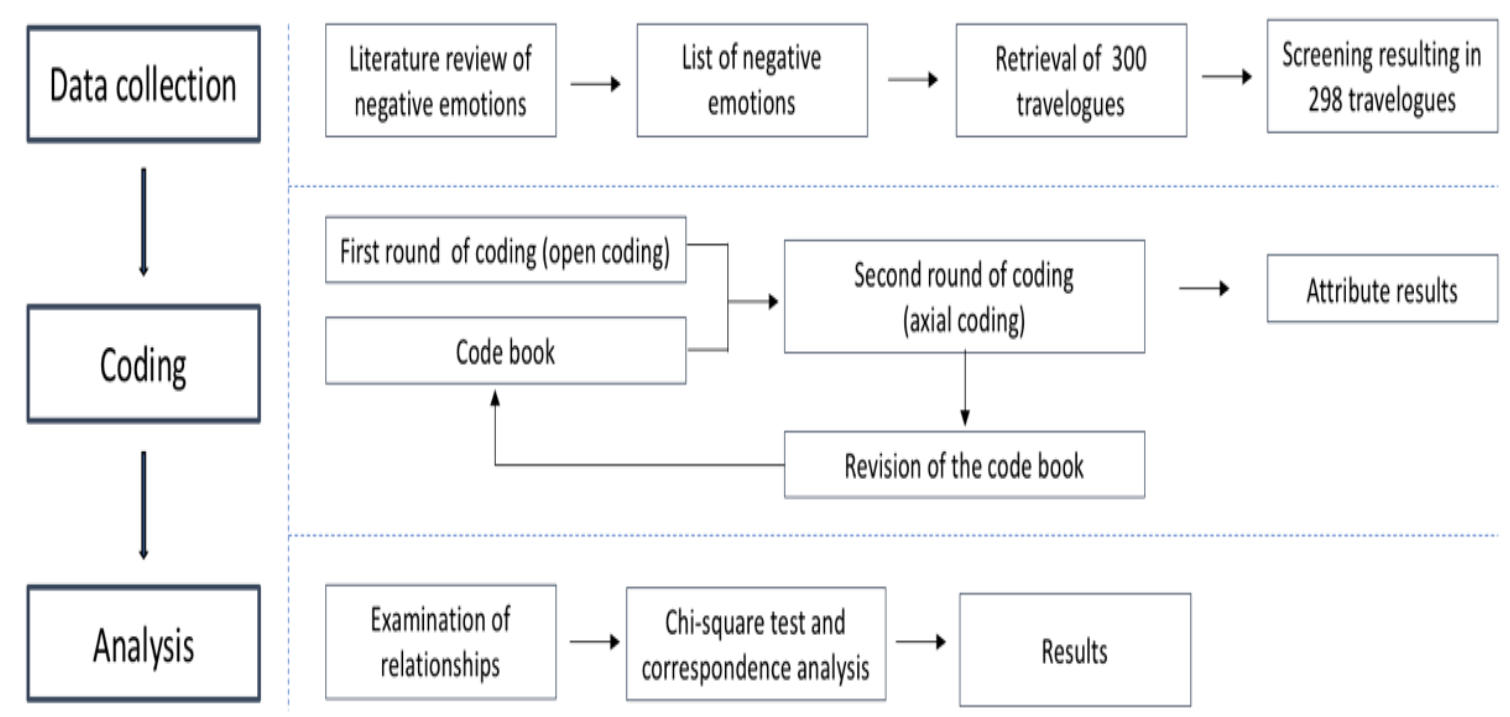


Figure 2. Correspondence map of the destination attributes and contextual factors

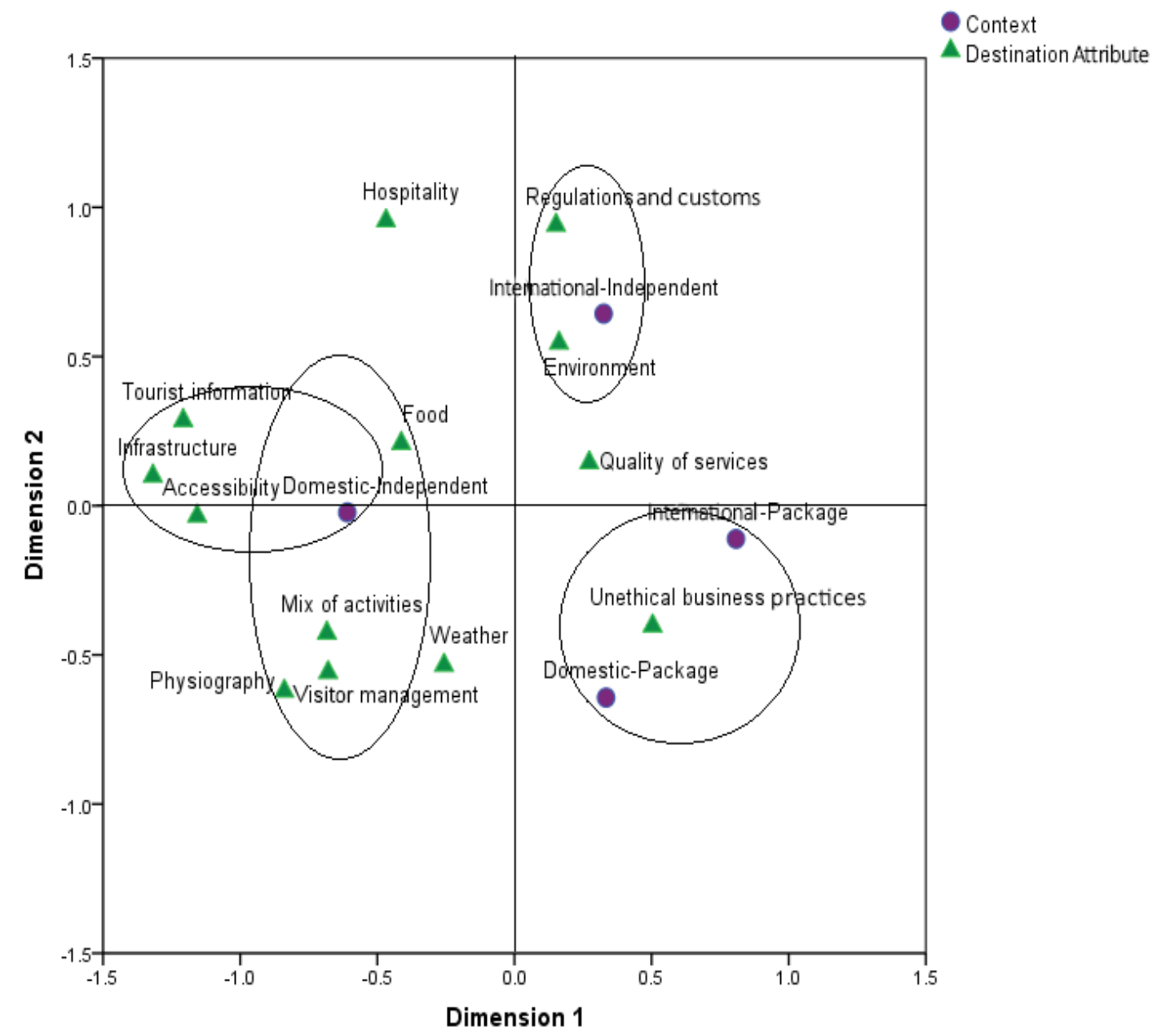

